\title{
One molecule of molybdopterin guanine dinucleotide is associated with each subunit of the heterodimeric Mo-Fe-S protein transhydroxylase of Pelobacter acidigallici as determined by SDS/PAGE and mass spectrometry
}

\author{
Wolfram REICHENBECHER ${ }^{1}$, Angelika RÜDIGER ${ }^{2}$, Peter M. H. KRONECK ${ }^{1}$ and Bernhard SCHINK ${ }^{\prime}$ \\ 1 Fakultät für Biologie, Universität Konstanz, Germany \\ ${ }^{2}$ Abteilung Molekulare Strukturforschung, Gesellschaft für Biologische Forschung, Braunschweig, Germany
}

\begin{abstract}
The molybdenum-containing iron-sulfur protein 1,2,3,5-tetrahydroxybenzene:1,2,3-trihydroxybenzene hydroxyltransferase (transhydroxylase) of Pelobacter acidigallici was investigated by various techniques including mass spectrometry and electron paramagnetic resonance. Mass spectrometry confirmed that the 133-kDa protein is a heterodimer consisting of an $\alpha$ subunit $(100.4 \mathrm{kDa})$ and a $\beta$ subunit $(31.3 \mathrm{kDa})$. The presence of a molybdenum cofactor was documented by fluorimetric analysis of the oxidized form A of molybdopterin. The enzyme contained $1.55 \pm 0.14$ mol pterin and $0.92 \pm 0.25 \mathrm{~mol}$ molybdenum $/ \mathrm{mol}$ enzyme $(133 \mathrm{kDa})$. Alkylation of the molybdenum cofactor with iodoacetamide formed di(carboxamidomethyl)-molybdopterin. Upon acid hydrolysis, $1.4 \mathrm{~mol} 5^{\prime} \mathrm{GMP} / \mathrm{mol}$ enzyme (133 kDa) was released indicating that molybdenum is bound by a molybdopterin guanine dinucleotide. The $\alpha$ and $\beta$ subunits were separated by preparative gel electrophoresis. Both subunit fractions were free of molybdenum but contained equal amounts of a fluorescent form of the molybdenum cofactor. Mass spectrometry at various $\mathrm{pH}$ values revealed that an acid-labile cofactor was released from the large subunit and also from the small subunit. At X-band, 5-25 K, transhydroxylase (as isolated) showed minor EPR resonances with apparent $g$ values around 4.3, 2.03 and, depending on the preparation, a further signal at $g$ of approximately 1.98 . This signal was still detectable above $70 \mathrm{~K}$ and was attributed to a $\mathrm{Mo}(\mathrm{V})$ center. Upon addition of dithionite, a complex set of intense resonances appeared in the region $g$ 2.08-1.88. From their temperature dependence, three distinct sites could be identified: the Fe-S center I with $g_{x, y, z}$ at approximately $1.875,1.942$ and $2.087\left(g_{\mathrm{av}} 1.968\right.$, detectable $\left.<20 \mathrm{~K}\right)$; the Fe-S center II with $g_{x, y, x}$ at approximately $1.872,1.955$ and $2.051\left(g_{\mathrm{av}} 1.959\right.$, detectable $\left.>20 \mathrm{~K}\right)$; and the $\mathrm{Mo}(\mathrm{V})$ center consisting of a multiple signal around $g 1.98$ (detectable $>70 \mathrm{~K}$ ).
\end{abstract}

Keywords: Pelobacter acidigallici; transhydroxylase; molybdenum enzymes; molybdopterin guanine dinucleotide; iron-sulfur cluster.

The strictly anaerobic bacterium Pelobacter acidigallici ferments trihydroxybenzenes via the phloroglucinol pathway to acetate and carbon dioxide (Brune and Schink, 1990a). The substrate spectrum of $P$. acidigallici is limited to 3,4,5-trihydroxybenzoate (gallic acid), 1,2,3-trihydroxybenzene (pyrogallol), 2,4,6-trihydroxybenzoate, and 1,3,5-trihydroxybenzene (phloroglucinol) (Schink and Pfennig, 1982).

During the initial steps of the phloroglucinol pathway, gallic acid is decarboxylated to pyrogallol which is subsequently transhydroxylated to phloroglucinol (Brune and Schink, 1990b). In this reaction a hydroxy group is transferred from 1,2,3,5-tetrahydroxybenzene $\left[\mathrm{Ph}(\mathrm{OH})_{4}\right]$ to pyrogallol yielding one molecule of $\mathrm{Ph}(\mathrm{OH})_{4}$ and one molecule of phloroglucinol (Fig. 1). The cosubstrate $\mathrm{Ph}(\mathrm{OH})_{4}$ is regenerated in this reaction, and is replen-

Correspondence to W. Reichenbecher, Fakultät für Biologie, Universität Konstanz, D-78434 Konstanz, Germany

Fax: +497531882966 .

Abbreviations. $\mathrm{Me}_{2} \mathrm{SO}$, dimethylsulfoxide; $\mathrm{Ph}(\mathrm{OH})_{4}$, 1,3,4,5-tetrahydroxybenzene.

Note. The novel amino acid sequence data reported here have been submitted to the SwissProt protein sequence database and are available under the accession numbers P80563, for the large subunit, and P80564, for the small subunit. ished during cell growth by an unknown reaction (Brune and Schink, 1990b; Haddock and Ferry, 1993).

Several enzymes catalyzing anaerobic net hydroxylations are known to contain molybdenum (Pilato and Stiefel, 1993). In those reactions, the hydroxyl oxygen atom introduced into the

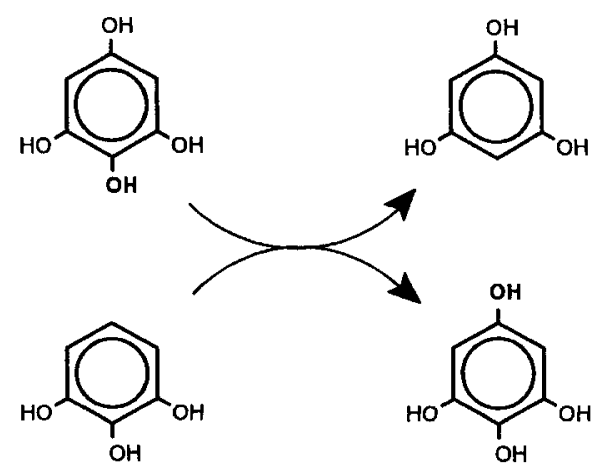

Fig. 1. Reaction of transhydroxylase of $\boldsymbol{P}$. acidigallici. Pyrogallol is transhydroxylated to phloroglucinol. 1,2,3,5-tetrahydroxybenzene serves as cosubstrate and coproduct (Brune et al., 1990b). 
substrate is derived from water (Hunt et al., 1958; Holm, 1990). Transhydroxylase was isolated from $P$. acidigallici and identified as a MoFeS protein with a heterodimeric structure (Reichenbecher et al., 1994). Here we report on the characterization and quantification of the molybdenum cofactor of transhydroxylase, its assignment to the subunits, and EPR experiments to analyze the molybdenum and Fe-S centers of this novel molybdenum enzyme.

\section{MATERIALS AND METHODS}

Analytical methods. Enzyme preparation. Transhydroxylase of $P$. acidigallici was purified as described previously (Reichenbecher et al., 1994).

Protein determination. The protein content was determined according to Bradford (1976) using BSA as a standard.

Molybdenum determination. The molybdenum content was determined by atomic absorption spectrometry as described in Reichenbecher et al. (1994).

Determination of the molybdenum content of fractions $o b$ tained by ultrafiltration of differently treated transhydroxylase extracts. Samples of transhydroxylase were mixed with an equal volume of the buffer used in gel electrophoresis, including SDS and mercaptoethanol, and exposed to $60^{\circ} \mathrm{C}$ and $95^{\circ} \mathrm{C}$ for varying periods of time. After treatment, aliquots were taken for denaturing electrophoresis (Laemmli, 1970) and for molybdenum determination. The remaining amount of the samples was subjected to ultrafiltration using Microconcentrators with a cut-off of $10000 \mathrm{Da}$ (Amicon). The molybdenum content was measured in the fractions obtained after ultrafiltration.

Biochemistry of the molybdenum cofactor. Oxidation of the pterin cofactor. The fluorescent form $\mathrm{A}$ of the pterin cofactor was prepared from 1-2 mg transhydroxylase in $500 \mu 50 \mathrm{mM}$ Tris/ $\mathrm{HCl}, 150 \mathrm{mM} \mathrm{NaCl}, \mathrm{pH} 7.2$, according to Johnson and Rajagopalan (1982) and Krüger and Meyer (1987). Buttermilk xanthine oxidase (Fluka) was used as a reference.

The pterin content of transhydroxylase was determined by oxidizing the cofactor to pterin-6-carboxylic acid with permanganate in alkaline solution according to Johnson and Rajagopalan (1982) and Karrasch et al. (1990a). Pterin-6-carboxylic acid (Fluka) was used as a reference.

Estimation of the molecular mass of the pterin cofactor. The molecular mass of the pterin cofactor in transhydroxylase was estimated by gel filtration following Krüger and Meyer (1987) and Karrasch et al. (1990a). The Sephadex G15 column $(1 \mathrm{~cm} \times 63 \mathrm{~cm})$ was equilibrated with FAD $(785 \mathrm{Da})$, FMN $(456 \mathrm{Da})$, riboflavin $(376 \mathrm{Da})$ and pterin-6-carboxylic acid (207 Da). Xanthine oxidase was used as a reference.

Carboxamidomethylation of the pterin. For alkylation of the molybdenum cofactor, $4.5 \mathrm{mg}$ transhydroxylase in $1 \mathrm{ml} 25 \mathrm{mM}$ Tris/ $\mathrm{HCl}, \mathrm{pH} 7.2$, was incubated with $15 \mathrm{mM}$ dithionite, $75 \mathrm{mg}$ SDS and $30 \mathrm{mg}$ iodoacetamide following the protocol of Karrasch et al. (1990b).

Acid hydrolysis of the molybdopterin dinucleotide. Purified enzyme (1.3 mg protein) in $25 \mathrm{mM}$ Tris $/ \mathrm{HCl}, \mathrm{pH} 7.2$, was acidified with concentrated sulfuric acid at a ratio of 1:20 (Frunzke and Meyer, 1991), boiled for $8 \mathrm{~min}$ and centrifuged for $10 \mathrm{~min}$. The supernatant was analyzed for nucleotides by HPLC using a $\mathrm{C}_{18}$ reverse-phase column $(4.6 \mathrm{~mm} \times 150 \mathrm{~mm}$, Beckman) at a flow rate of $1 \mathrm{ml} / \mathrm{min}$ equilibrated with $20 \mathrm{mM}$ sodium phosphate, $\mathrm{pH}$ 3.5. 5'AMP (Boehringer Mannheim), 5'GMP, 5'TMP, and $5^{\prime} \mathrm{CMP}$ (Sigma) were used as references. Spectra were recorded by a scanning detector module 167 (Beckman).

Preparation of subunits. $1 \mathrm{mg}$ transhydroxylase in $400 \mu \mathrm{l}$ $50 \mathrm{mM}$ triethanolamine, $\mathrm{pH} 7.5$, containing $0.9 \mathrm{~mol} \mathrm{Mo} / \mathrm{mol}$ en- zyme was mixed with $670 \mu \mathrm{l}$ sample buffer containing $60 \mathrm{mM}$ Tris/ $\mathrm{HCl}, \mathrm{pH} 6.8,2 \% \mathrm{SDS}$, and $10 \%$ glycerol. The mixture was boiled for $3 \mathrm{~min}$, cooled, and loaded on a $4 \%$ stacking gel $(17 \times 3 \times 0.2 \mathrm{~cm})$ with a $12 \%$ separating gel $(17 \times 10 \times 0.2 \mathrm{~cm})$ containing $0.1 \%$ SDS. Electrophoresis was performed for $5 \mathrm{~h}$ at $100 \mathrm{~mA}$. The outer lanes of the gel were cut off and stained with Coomassie brilliant blue R-250. Gel pieces of the other lanes containing denatured enzyme subunits were cut out and collected separately. A third gel piece was cut out as a reference. Gel pieces were homogenized between small plastic plates. Polypeptides were extracted with $5 \mathrm{ml} 10 \mathrm{mM}$ Tris/HCl, $\mathrm{pH} 7.2$, containing $0.1 \%$ SDS, twice for $2 \mathrm{~h}$, and decanted through a paper filter. Fractions were concentrated to $1 \mathrm{ml}$ using a Centriprep 10. Aliquots were applied to electrophoresis using the Mini Protean II gel apparatus from BioRad for determining separation efficiency. The molybdenum content in both preparations was measured by atomic absorption spectrometry. Aliquots of the mixtures were applied to gel filtration using a Superose 12 10/30 column equilibrated with $50 \mathrm{mM}$ Tris $/ \mathrm{HCl}, \mathrm{pH} 7.6$, containing $150 \mathrm{mM} \mathrm{NaCl}$. Fractions absorbing at $280 \mathrm{~nm}$ were collected, lyophilized and redissolved in $50 \mathrm{mM}$ Tris/ $\mathrm{HCl}$, pH 7.6. Samples were subjected to iodine oxidation as cited, but the chromatographic step was omitted. Fluorescence was measured in $0.1 \mathrm{M} \mathrm{NaOH}$.

N-terminal amino acid sequence. Subunits of the purified transhydroxylase were separated on a $12 \%$ SDS/polyacrylamide gel. Semidry-blotting on a poly(vinylidene difluoride) membrane was performed according to Jungblut et al. (1990). After staining (Coomassie brilliant blue R-250), destaining and drying of the membrane, the N-terminal sequences were determined by automated Edman degradation in a 477A Protein Sequencer (Applied Biosystems).

Mass spectrometry. Matrix-assisted laser desorption/ionization-time-of-flight (MALDI-TOF) mass spectrometry was performed using a Bruker REFLEX ${ }^{\mathrm{TM}}$-time-of-flight mass spectrometer (Ruidiger et al., 1995). All spectra were recorded in the linear mode, with an acceleration voltage of $30 \mathrm{kV}$. The mass spectrometer was calibrated with BSA (Sigma, B-2518) and glucose dehydrogenase from Acinetobacter calcoaceticus (Boehringer Mannheim) as external standards. The initial analyte mixture consisted of approximately $10 \mathrm{pmol} / \mu \mathrm{l}$ transhydroxylase dissolved in $10 \mathrm{mM}$ ammonium acetate, $\mathrm{pH}$ 6.1. This solution was analyzed directiy as described below. In a second analytical step the enzyme solution was diluted with $0.1 \%$ trifluoroacetic acid $(1: 1$, by vol.) and submitted again to mass spectrometric analysis. The $\mathrm{pH}$ values of the buffers mixed with matrix solution were checked with a $\mathrm{pH}$ electrode. Sinapic acid was used as ultraviolet-absorbing matrix. Equal volumes of the analyte solution and a saturated solution of sinapic acid in acetonitrile $0.1 \%$ trifluoroacetic acid $(2: 3$, by vol.) were mixed and spotted on a stainless steel tip. Mass-assignment accuracies range between $0.1-0.2 \%$ as estimated from several independent measurements, which is typical of this method (Carr et al., 1991).

Spectroscopy. Electronic spectra were recorded with an Uvikon 930 spectrophotometer (Kontron). Fluorescence spectra were measured on the LS 50 fluorimeter (Perkin Elmer). Electron paramagnetic resonance spectra at X-band and $100 \mathrm{kHz}$ modulation frequency were recorded on an ESP 300 spectrometer (Bruker). The magnetic field was measured with an NMR gauss meter calibrated with diphenylpicryl-hydrazyl and Mn(II) in $\mathrm{MgO}$. The frequency was monitored with a frequency counter. Spectra were recorded under conditions of non-saturating microwave power, and were stored on hard disk for manipulation with ESP 300 software. The temperature in the range $5-100 \mathrm{~K}$ was maintained with a Helitran LTD-100 C system (Air Products). The samples $(2 \mathrm{mg}$ protein in $250 \mu 150 \mathrm{mM}$ triethanolamine 


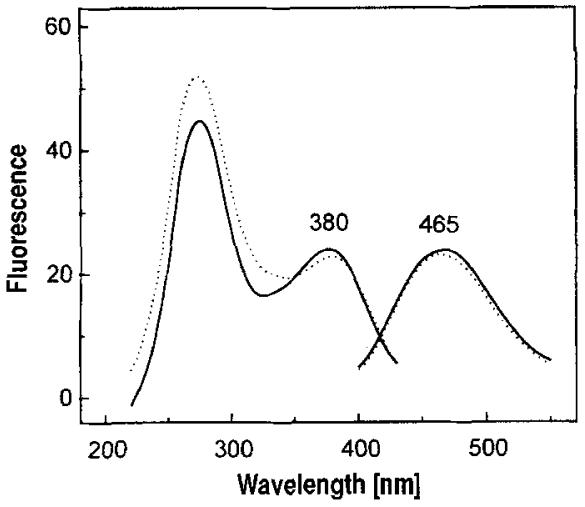

Fig. 2. Fluorescence spectra of the iodine-oxidized pterin cofactor of transhydroxylase (solid line) and xanthine oxidase (dashed line), recorded in $0.1 \mathrm{M} \mathrm{NaOH}$. Excitation was at $380 \mathrm{~nm}$ and emission at $465 \mathrm{~nm}$ wavelength

buffer, $\mathrm{pH} 7.5$ ) were frozen in quartz tubes ( $\phi \mathrm{i} 3-3.5 \mathrm{~mm}$ ) in liquid nitrogen. A sample of reduced enzyme was obtained by adding dithionite dissolved in buffer under an atmosphere of argon. The $g$-values were assigned on the basis of values reported in the literature. Spin concentration was estimated according to Aasa and Vänngård (1975) with $\mathrm{Cu}(\mathrm{II}) \mathrm{SO}_{4}$ in $\mathrm{HCl} /$ $\mathrm{HClO}_{4}$ as a standard (Vänngård, 1972).

\section{RESULTS}

Characterization of the molybdenum cofactor. Oxidation of iodine. After iodine treatment of pure transhydroxylase preparation, a fluorescent compound was extracted which exhibited an excitation maximum at $380 \mathrm{~nm}$ and an emission maximum at $465 \mathrm{~nm}$ (Fig. 2). The spectrum of xanthine oxidase (Fig. 2), which served as reference (Johnson et al., 1980) was nearly identical with that of transhydroxylase indicating that the latter contained molybdopterin too.

Molecular mass. For the molybdopterin of transhydroxylase, a relative molecular mass of $740 \mathrm{Da}$ was estimated compared with $315 \mathrm{Da}$ for the molybdopterin of xanthine oxidase (data not shown). This is in agreement with the presence of a molybdopterin dinucleotide in transhydroxylase.

Pterin quantification. The amount of pterin cofactor present in transhydroxylase was quantified fluorimetrically after oxidation with permanganate using pterin-6-carboxylic acid as a standard. $1.55 \pm 0.14(1.70,1.43,1.51) \mathrm{mol}$ pterin-6-carboxylic acid was found per mol enzyme (133 kDa).

Di(carboxamidomethyl)-molybdopterin. The molybdenum cofactor of transhydroxylase was subjected to alkylation with iodoacetamide after release in the presence of SDS. After removal of the bulk of SDS, a peak eluted from the HPLC column with absorption maxima at $252 \mathrm{~nm}, 286 \mathrm{~nm}$ and $362 \mathrm{~nm}$ (Fig. 3). This peak is typical of a di(carboxamidomethyl)-molybdopterin derivative and resembles the spectrum described for di(carboxamidomethyl)-molybdopterin guanine dinucleotide (Johnson et al., 1990). No other peaks eluting from the column exhibited absorbance above $300 \mathrm{~nm}$. The $A_{286} / A_{362}$ ratio is about 2 , in contrast to those of 4, found by Johnson et al. (1990), and 3.3, found by Frunzke et al. (1993). This may indicate that the corresponding peak was still contaminated with SDS. Addition of other denaturing agents such as dimethylsulfoxide $\left(\mathrm{Me}_{2} \mathrm{SO}\right.$, Johnson et al., 1990), or guanidine/HCl (Frunzke et al., 1993), did not release a di(carboxamidomethyl)-molybdopterin derivative from transhydroxylase. Treatment with SDS released only a small amount of the di(carboxamidomethyl) derivative from transhy-

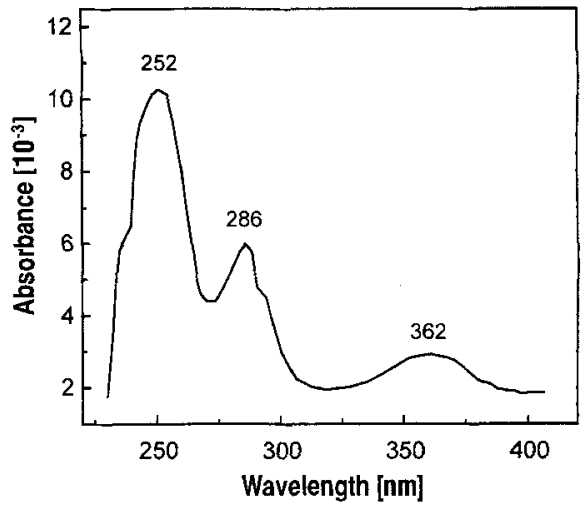

Fig. 3. Absorption spectrum of the di(carboxamidomethyl)-molybdopterin dinucleotide of transhydroxylase generated by alkylation with iodoacetamide in the presence of SDS after separation by HPLC.

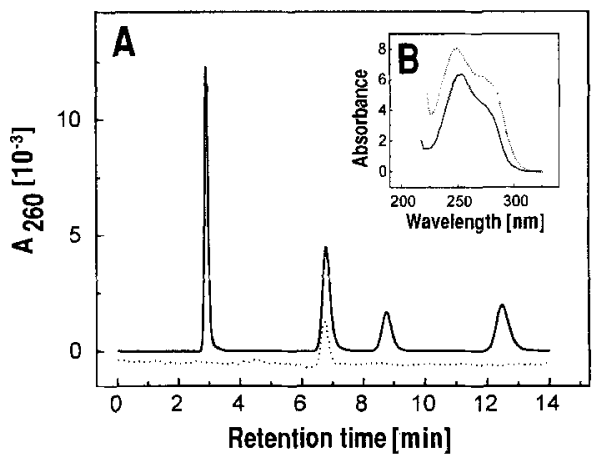

Fig. 4. Type of nucleotide released from the molybdenum cofactor of transhydroxylase upon treatment with sulfuric acid. The lower chromatogram $(\cdots \cdots)$ shows a peak with the same retention time $(6.8 \mathrm{~min})$ and the same absorption spectrum $(\cdots, .$, inset $)$ as authentic 5 'GMP ( - , inset). The upper line ( $\longrightarrow$ shows an HPLC chromatogram of $5^{\prime} \mathrm{CMP}$ (2.9 min), 5'GMP (6.8 min), 5'AMP (8.8 min), and 5'TMP (12.4 min).

droxylase (Fig. 3). Therefore the derivative was not isolated or subjected to further studies (Karrasch et al., 1990b; Johnson et al., 1990).

Molybdopterin guanine dinucleotide. $10.6 \mathrm{nmol}$ transhydroxylase with a molybdenum content of $0.86 \mathrm{~mol} \mathrm{Mo} / \mathrm{mol}$ enzyme was subjected to acid hydrolysis. A single compound eluted from the column which produced a peak at the same time (Fig. 4, $6.8 \mathrm{~min}$ ) and showed the same absorption spectra (Fig. 4) as authentic 5'GMP. 5'CMP (2.9 min), 5'AMP ( $8.8 \mathrm{~min})$ and 5'TMP (12.4 min) had clearly distinct retention times (Fig. 4). For transhydroxylase a molar content of $1.4 \mathrm{~mol} \mathrm{GMP/}$ mol enzyme was calculated. From this result it was concluded that two molecules of molybdopterin guanine dinucleotide are present for each enzyme heterodimer.

Assignment of the molybdenum cofactor to the subunits. Both subunits were separated by denaturing gel electrophoresis. Polypeptides were cut out of the non-stained gel and released by pulverization and diffusion. Gel electrophoresis of the two preparations showed that the subunits were separated successfully without cross-contamination (Fig. 5a). Neither contained any molybdenum, as was confirmed by atomic absorption spectrometry measurements. Both subunit preparations were tested for presence of the molybdenum cofactor by generating the fluorescent form A. The recorded spectra were corrected for a blank gel piece as a reference. In both subunits equal amounts of a 

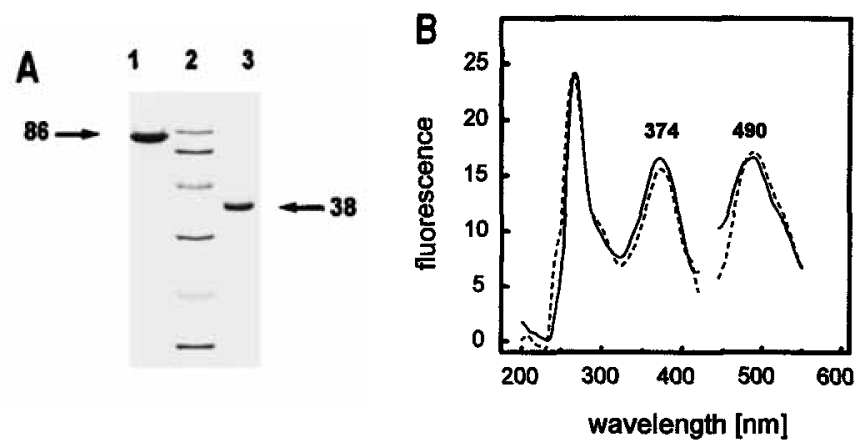

Fig. 5. Assignment of the molybdenum cofactor of transhydroxylase to the enzyme subunits. (A) Gel electrophoresis of the preparations of the transhydroxylase subunits after separation by preparative gel electrophoresis. Lane 1, preparation of the large subunit ( $86 \mathrm{kDa})$; lane 2, calibration proteins with a molecular mass of (in $\mathrm{kDa}$ ) $94,67,43,30,20.1$, and 14.4; lane 3, preparation of the small subunit ( $38 \mathrm{kDa}$ ). (B) Fluorescence spectra of the iodine-oxidized molybdenum cofactor of the large (solid line) and the small (dashed line) subunit from transhydroxylase recorded in $0.1 \mathrm{M} \mathrm{NaOH}$. Equal amounts of the subunit preparations were used for fluorimetry. Excitation was at $380 \mathrm{~nm}$ and emission at $485 \mathrm{~nm}$ wavelength.
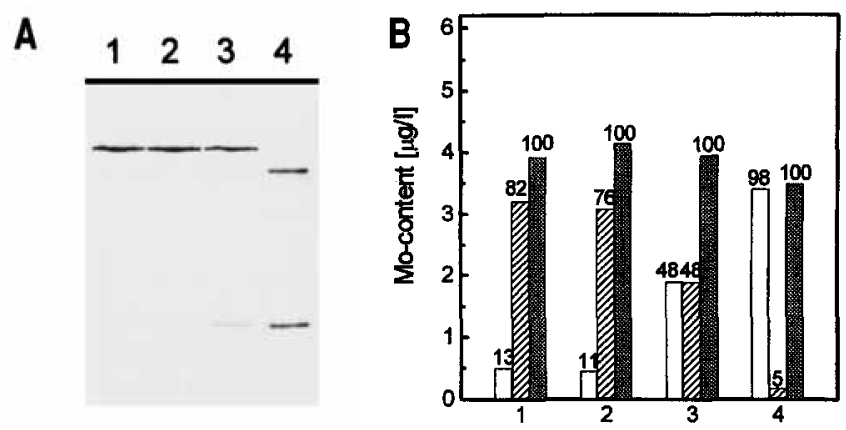

Fig. 6. Molybdenum content in fractions of pretreated transhydroxylase samples obtained by ultrafiltration (10 000 Da cut-off). (A) Separation of purified transhydroxylase by SDS/PAGE after various pretreatments. SDS/PAGE gel was $10 \%$ and stained with Coomassie brilliant blue. $1.5 \mu \mathrm{g}$ protein was loaded in each lane. Pretreatments: lane 1 , heating for $15 \mathrm{~min}$ at $60^{\circ} \mathrm{C}$; lane 2 , heating for $30 \mathrm{~min}$ at $60^{\circ} \mathrm{C}$; lane 3 , heating for $2 \mathrm{~h}$ at $60^{\circ} \mathrm{C}$; lane 4 , heating for $4 \mathrm{~min}$ at $95^{\circ} \mathrm{C}$. (B) Molybdenum content of different fractions of the samples loaded onto the gel in (a). (疄) Total fraction before ultrafiltration; ( $\square$ ) filtrated fraction, ( $(Z A)$ retained fraction. The ratio of both fractions compared with the total fraction is given as a percentage.

molybdopterin derivative were found, exhibiting maxima at $374 \mathrm{~nm}$ and $490 \mathrm{~nm}$ (Fig. 5 b).

This result confirmed that two molecules of molybdenum cofactor were present for each heterodimer, and one molecule is bound to each subunit.

Molybdenum content. The molybdenum content was $0.92 \pm 0.25 \mathrm{~mol} \mathrm{Mo} / \mathrm{mol}$ enzyme $(133 \mathrm{kDa})$ as a mean of five enzyme preparations $(0.82,0.69,0.98,0.73$, and $1.36 \mathrm{~mol} \mathrm{Mo} /$ mol enzyme). Transhydroxylase samples were heated at $60^{\circ} \mathrm{C}$ and $95^{\circ} \mathrm{C}$ for varying periods of time, and aliquots were subjected to gel electrophoresis. Molybdenum was determined in each sample and in the fractions obtained after ultrafiltration. Thus, the protein was disintegrated stepwise into its subunits. After $15 \mathrm{~min}$ and $30 \mathrm{~min}$ at $60^{\circ} \mathrm{C}$, only small amounts of the subunits appeared (Fig. 6a). About $10 \%$ of the total molybdenum content was found in the filtered fractions. After $2 \mathrm{~h}$ incubation, a larger part of the enzyme disintegrated and the molyb-

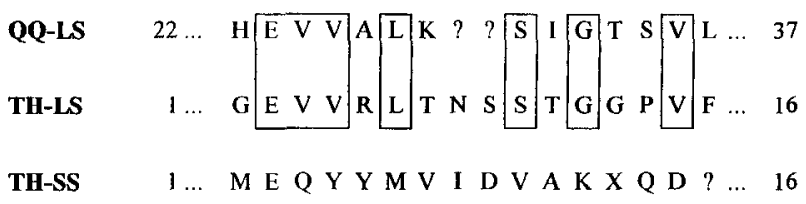

Fig. 7. Alignment of the N-terminal amino acids of the large subunit (LS) of quinaldine oxidoreductase (QQ) from Arthrobacter spec. Rï 61a with the large subunit (LS) of transhydroxylase (TH) of $P$. acidigallici. The N-terminus of the small subunit (SS) of transhydroxylase is listed below.

denum was found in the retained fraction and the filtrated fraction to equal amounts (Fig. 6b). Complete denaturation was achieved by heating at $95^{\circ} \mathrm{C}$ for $4 \mathrm{~min}$. This treatment released the molybdenum almost completely into the filtrate fraction. Obviously, disintegration into the subunits and liberation of molybdenum were directly correlated.

N-terminal amino acid sequences. The sequences of the first 15 amino acids from the $\mathrm{N}$-termini of the two subunits of transhydroxylase are given in Fig. 7. Several data banks were searched for corresponding sequences: SWISS (SwissProt Library), YPROT (Protein Library), and SALK (Kinase Library). The nearest correspondence to the sequence of the large subunit was a $67 \%$ identity with ribulose bisphosphate carboxylase between positions 372 and 384 in a 12-amino-acid overlap, and to the sequence of the small subunit a $55 \%$ identity with an 11 amino acid overlap of anthranilate synthase between positions 171 and 192. These correspondences are obviously random and not regarded as significant.

The N-termini of both subunits were also compared with $\mathrm{N}$ termini from other molybdenum-containing and tungsten-containing enzymes (De Beyer and Lingens, 1993; Schübel et al., 1995; Krafft et al., 1992; Kretzer et al., 1993; Peschke and Lingens, 1991; Schmitz et al., 1992; Thoenes et al., 1994; White et al., 1991, 1993). Residues 1-10 of the large subunit were similar to residues $23-31$ of the large subunit of quinaldine oxidoreductase from Arthrobacter spec. Rü 61a (De Beyer and Lingens, 1993; Fig. 7).

Mass spectrometry. Mass spectrometry of transhydroxylase from $P$. acidigallici showed two signal groups, one in the mass range of $16-66 \mathrm{kDa}$, and another one in the mass range of $100-266 \mathrm{kDa}$ (Fig. 8).

The signals at $32 \mathrm{kDa}$ were attributed to singly charged ion species with the corresponding double-charged species at $16 \mathrm{kDa}$. A small peak at $66 \mathrm{kDa}$ arose from a small amount of the 32-kDa dimer. The peaks displayed a doublet structure (Fig. 8A and B). With decreasing $\mathrm{pH}$, the masses of the observed peak fractions shifted to lower values, and the mass increment between the signal lines of one doublet decreased.

In the second signal group at $100-266 \mathrm{kDa}$ (Fig. 8C and D), the single-charged molecules appeared with the corresponding group of double-charged peaks at $100-133 \mathrm{kDa}$. A small signal appearing at $50 \mathrm{kDa}$ (data not shown) as well as the differences in the distribution of intensities between the singlecharged and double-charged peak groups indicated that the peak at $100 \mathrm{kDa}$ (Fig. $8 \mathrm{C}$ ) represents both single-charged and doublecharged species. The mass differences between the peaks I and III (Fig. 8C and D) indicate that acquire of a second charge is connected with mass decrease of approximately $1.4 \mathrm{kDa}$. Lowering the $\mathrm{pH}$ of the analyte from 5.1 to 4.6 before matrix addition led to a decrease of the experimentally observed molecular masses, similar to the effect observed for the signals in the lower mass range. The intensity pattern for the peak groups in 

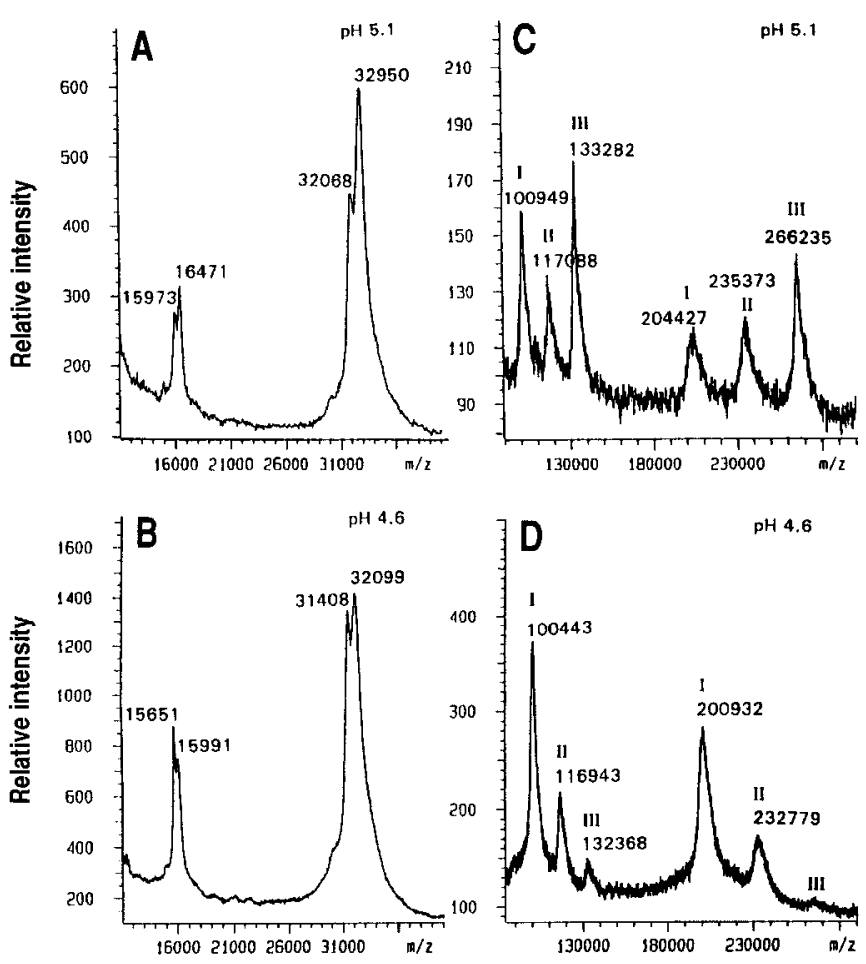

Fig. 8. Mass spectra of transhydroxylase measured under different pH conditions. (A) and (B) Signals of the small subunit recorded at $\mathrm{pH} 5.1$ and $\mathrm{pH} 4.6$, respectively. Peaks of both the single-charged and double-charged ions are displayed. (C) and (D) Peaks recorded in the mass range above $100 \mathrm{kDa}$ at $\mathrm{pH} 5.1$ and $\mathrm{pH} 4.6$. In both panels doublecharged and single-charged peaks of the same species are indicated with the same numbers, I to III. Peak III corresponds to the heterotetramer composed of two small and two large polypeptides.

the high mass range changes strongly. The peak of highest intensity is peak III for $\mathrm{pH} 5.1$, and peak I for $\mathrm{pH} 4.6$.

Electron paramagnetic resonance at X-band, 5-100 K. Enzyme as isolated. Depending on the preparation, transhydroxylase exhibited a minor resonance at low magnetic field, $g$ 4.3, due to adventitious iron, and in the high-field region a signal with an upward feature at $g$ of approximately 2.03, (base line crossing at $g=2.01$ ), and a signal around $g$ of 1.98 . Above $30 \mathrm{~K}$, only the signal at $g$ of approximately 1.98 was detectable. These signals at high magnetic field were observed in a sample of transhydroxylase which had been prepared in the presence of $2 \mathrm{mM}$ thioglycolate.

Enzyme reduced with dithionite. At $5-10 \mathrm{~K}$, the dithionitereduced protein gave a complex set of resonances in the $g 2$ region (Fig. 9A), with major lines at $g$ 2.087, 2.051, 1.958, 1.942 and 1.875 . At approximately $30 \mathrm{~K}$, the resonances at $g$ 2.087 and 1.942 had disappeared completely, with lines left at $g$ 2.051, 1.955 and 1.872 (Fig. 9 B); these resonances were still detectable around $45 \mathrm{~K}$. Furthermore, a multiline signal around $g 1.98$ became detectable. This signal, with apparent $g$ values at 2.02 and 1.97 , and hyperfine splittings of $1.2-1.4 \mathrm{mT}$, was the only signal observed at $70 \mathrm{~K}$ (Fig. 9C).

\section{DISCUSSION}

Molybdopterin guanine dinucleotide and Fe-S centers both form the active center of transhydroxylase of $P$. acidigallici. Two molecules molybdopterin guanine dinucleotide and one molecule molybdenum per enzyme heterodimer have been found.

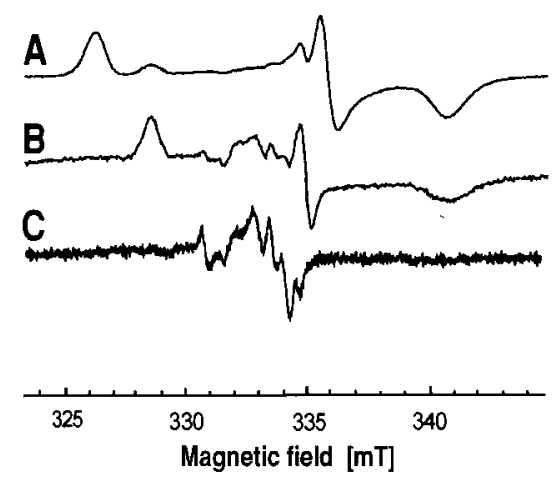

Fig. 9. Electron paramagnetic resonance spectra of transhydroxylase of Pelobacter acidigallici at $10 \mathrm{~K}(\mathrm{~A}), 29 \mathrm{~K}(\mathrm{~B})$, and $70 \mathrm{~K}$ (C). Approximately $10 \mathrm{mg}$ enzyme $/ \mathrm{ml}$ in $50 \mathrm{mM}$ triethanolamine, $250 \mathrm{mM} \mathrm{NaCl}$, $\mathrm{pH} 7.3$, reduced with dithionite was applied; instrument settings were $100 \mathrm{kHz}$ modulation; modulation amplitude, $1.0 \mathrm{mT}$; power, $2 \mathrm{~mW}$; microwave frequency, approximately $9.3 \mathrm{GHz}$; receiver gain, $1 \times 10^{5}$ Spectrum A represents the average of 5 scans compared with 25 scans for $\mathrm{B}$ and $\mathrm{C}$.

Both subunits contained equal amounts of the molybdenum cofactor.

Structure of transhydroxylase as revealed by mass spectrometry. Mass spectrometry confirmed that transhydroxylase is composed of two different subunits (Reichenbecher et al., 1994): a peak group in the range 16-66 Da was attributed to the small subunit and the assembly of peaks in the range from $100-266 \mathrm{Da}$ was caused by the large subunit. The molecular mass of the heterodimer was $133282 \pm 200 \mathrm{Da}$ which is in good agreement with the value of $127 \mathrm{kDa}$ determined by gel filtration in the presence of SDS (Reichenbecher et al., 1994). For the small subunit a molecular mass of $31302 \pm 32 \mathrm{Da}$ and for the large subunit a molecular mass of $100443 \pm 200 \mathrm{Da}$ was measured corresponding to $38 \mathrm{kDa}$ and $86 \mathrm{kDa}$ as determined by electrophoresis (Reichenbecher et al., 1994). The difference of about $1.5 \mathrm{kDa}$ between the mass of the heterodimer and the sum of the masses of the subunits was probably due to the loss of cofactor.

The results obtained agree with the reported tendency of transhydroxylase to form multimeric aggregates (Reichenbecher et al., 1994): the 266235 \pm 300 -Da peak III in Fig. $8 \mathrm{C}$ was attributed to a heterotetramer consisting of two small subunits, two large subunits and additional cofactor. The mass spectra showed that upon lowering the $\mathrm{pH}$ of the analyte solution two fragments with a mass corresponding to a molybdopterin dinucleotide could remain either with the large or with the small subunit. Peaks I and II in Fig. 8C were apparently formed by multimers composed of two large subunits and two large and one small subunit, respectively. According to the mass increment of $30.8 \mathrm{kDa} \pm 0.4 \mathrm{kDa}$ between peaks II and III (Fig. $8 \mathrm{C}$ ) the small subunit disintegrated with the cofactors remaining with the multimer. When the multimers forming peaks I and III took a second charge this was connected with a mass loss of $1.4 \pm 0.2 \mathrm{kDa}$ which was probably equivalent to two molecules molybdopterin guanine dinucleotide. The small subunit of transhydroxylase caused singly charged duplicate peaks at $\mathrm{pH} 5.1$ (Fig. 8A) and pH 4.6 (Fig. 8B). The mass differences of $882 \pm 32 \mathrm{Da}$ (Fig. 8A) and $691 \pm 32 \mathrm{Da}$ (Fig. 8 B) indicated that two molecules of the molybdenum cofactor were lost stepwise from the small subunit by lowering the $\mathrm{pH}$. When taking a second charge, the 32950-Da peak (Fig. 8A), the 32099-Da peak (Fig. 8B) and the 31408-Da peak (Fig. 8B) lacked masses of around $122 \mathrm{Da}, 117 \mathrm{Da}$ and $106 \mathrm{Da}$, respectively, calculated for 
the singly charged ions. This could be attributed to the loss of a molybdenum-containing fragment with, e.g., oxygen ligands (Mo, $96 \mathrm{Da} ; \mathrm{O}, 16 \mathrm{Da}$ ). From the double-charged ion at $\mathrm{m} / \mathrm{z}$ of 15651 , a minimum mass of $31302 \pm 32 \mathrm{Da}$ for the small subunit was calculated.

The molybdenum cofactor. Upon acid treatment and iodine oxidation, the fluorescent form A of the molybdopterin was released from transhydroxylase. An estimated mass of $740 \mathrm{Da}$ gave evidence of a dinucleotide type of molybdopterin. Alkylation with iodoacetamide led to a spectrum typical of a di(carboxamidomethyl)-molybdopterin derivative indicating the presence of the well studied molybdenum cofactor. Quantification of the pterin suggests that two molecules molybdenum cofactor are present in each enzyme dimer. A mean of $1.55 \mathrm{~mol}$ $\mathrm{pterin} / \mathrm{mol}$ enzyme was found. Values of $0.6-0.9$ (Karrasch et al., 1990a) and 1.6 (White et al., 1991) mol pterin/mol enzyme corresponding to $1 \mathrm{~mol}$ or $2 \mathrm{~mol}$ cofactor have been reported in the literature. Upon acid treatment $1.4 \mathrm{~mol}$ GMP were released from the enzyme indicating that two molecules molybdopterin guanine dinucleotide are present. Molybdopterin guanine dinucleotide has been found in various molybdoenzymes such as $\mathrm{Me}_{2} \mathrm{SO}$ reductase (Johnson et al., 1990), nitrate reductases (Frunzke et al., 1993), formate dehydrogenases (Johnson et al., 1991 ; Rajagopalan and Johnson, 1992) and formylmethanofuran dehydrogenases (Karrasch et al., 1990b; Börner et al., 1991). With the exception of $\mathrm{Me}_{2} \mathrm{SO}$ reductase of Rhodobacter sphaeroides, these enzymes contain Fe-S centers as additional cofactors. Formate dehydrogenase isolated from Methanobacterium formicicum is the only enzyme of this group which contains FAD (Schauer and Ferry, 1986). Transhydroxylase lacks FAD but contains molybdopterin guanine dinucleotide and $\mathrm{Fe}-\mathrm{S}$ centers. Beyond that, there are no common characteristics of the subunit composition of these enzymes.

Considering the structural composition and cofactor constitution molybdoenzymes containing molybdopterin cytosine dinucleotide or molybdopterin as molybdenum cofactor form a comparably homogeneous group of enzymes (Kretzer et al., 1993). They contain three subunits with molecular masses around 85,32 and $20 \mathrm{kDa}$. The cofactors are molybdopterin cytosine dinucleotide or molybdopterin, FAD, and Fe-S centers (Kretzer et al., 1993), of which some have been shown to be [2Fe-2S] clusters. The 6-hydroxynicotinate dehydrogenase of Bacillus niacini is the only enzyme grouped herein with molybdopterin guanine dinucleotide instead of molybdopterin cytosine dinucleotide. Transhydroxylase also contains molybdopterin guanine dinucleotide and $[2 \mathrm{Fe}-2 \mathrm{~S}]$ clusters. FAD or a third subunit has not been observed in transhydroxylase. The molecular mass of the small subunit $(33 \mathrm{kDa})$ corresponds to that of the middle-sized subunit ( $32 \mathrm{kDa}$ ) of the molybdopterin cytosine dinucleotide containing enzymes, the large subunit of transhydroxylase $(100 \mathrm{kDa})$ equals the sum of the large and the small subunit $(85 \mathrm{kDa}$ and $20 \mathrm{kDa}$ ). Molybdopterin-cytosine-dinucleotide containing enzymes comprise $1 \mathrm{~mol}$ FAD and $1 \mathrm{~mol}$ molybdenum cofactor per mol enzyme protomer (Kretzer et al., 1993). It remains to be shown by sequence analysis if the second pterin molecule in transhydroxylase substitutes for the lacking flavin molecule.

In the preparations used, we found only $0.81 \mathrm{~mol}$ molybdenum/mol enzyme, compared with 1.1 mol reported by Reichenbecher et al. (1994). Usually the molybdenum content determined in various proteins is smaller than the molybdenum content assumed (Adams and Mortenson, 1985). Provided that the protein content has been determined correctly this difference could be caused by interference with sulfate or phosphate during the determination (Johnson, 1988), by metal loss during prepara- tion, or by the coexistence of a metal and de-metal form of the protein (Ventom et al., 1988). In the case of transhydroxylase either $50 \%$ of the molybdenum was lost during the purification, or the stoichiometry is $2 \mathrm{~mol}$ pterin $/ 1 \mathrm{~mol}$ metal as found for the tungsten-dependent aldehyde ferredoxin oxidoreductase of Pyrococcus furiosus (Chan et al., 1995). This enzyme also lacks flavin.

Assignment of the molybdenum cofactor to the subunits. Upon separation of both subunits of the enzyme by denaturing gel electrophoresis, equal amounts of molybdopterin were found in both subunits. No pterin fluorescence was found in a gel piece localized between the bands of the subunits making it improbable that cofactor was transferred between the subunits during electrophoresis. Dissociation and reassociation of the cofactor during sample preparation before electrophoresis cannot be discounted but is supposed to be highly unlikely because of the equal amount of cofactor in both subunit preparations. Instead, we conclude that upon heating in the presence of $1.3 \%$ SDS the protein was separated into its subunits but not fully denatured which allowed the molybdenum cofactor to remain bound to the subunits. This notable stability of transhydroxylase corresponds with the failure to release a di(carboxamidomethyl) derivative of the cofactor from transhydroxylase upon treatment with $\mathrm{Me}_{2} \mathrm{SO}$ or guanidine $/ \mathrm{HCl}$, with the release of only small amounts of a di(carboxamidomethyl) derivative at an increased SDS concentration of $7.5 \%$, and with the survival of a high proportion of enzymatic activity in the presence of $1 \%$ SDS (Reichenbecher et al., 1994). Mass spectrometry confirmed the presence of an acid-labile cofactor of 690-880 $\mathrm{Da}$ in the subunits. This corresponds to the mass of one molecule molybdopterin guanine dinucleotide $(737 \mathrm{Da})$ with or without molybdenum $(96 \mathrm{Da})$ and, e.g., two oxygen ligands (32 Da). Acid treatment is commonly used to release fluorescent forms of the cofactor (Hageman and Rajagopalan, 1986). The results of quantification of pterin and nucleotide content suggest that transhydroxylase contains $2 \mathrm{~mol}$ molybdopterin guanine dinucleotide. From these results we conclude that one molecule molybdopterin guanine dinucleotide is bound to each subunit.

From sequence analysis of several molybdenum-containing enzymes it has been deduced that the molybdenum cofactor is bound to the large subunit (Wootton et al., 1991). The prototype is the $82-\mathrm{kDa}$ homomer $\mathrm{Me}_{2} \mathrm{SO}$ reductase of $R$. sphaeroides which contains one molybdenum cofactor as the only cofactor (Satoh and Kurihara, 1987; Johnson et al., 1990). Possible linkage of the molybdenum cofactor also to other subunits of an enzyme has rarely been discussed. Here we present biochemical evidence that the molybdenum cofactor of transhydroxylase is bound to both the large and the small subunit. Mass spectrometry confirms this result. The results of the metal determination suggest that one molybdenum atom is bound to two molecules of the cofactor, similar to the tungsten-containing aldehyde ferredoxin oxidoreductase of $P$. furiosus (Chan et al., 1995). Consequently, the metal should be located between both subunits. We have shown that disintegration of transhydroxylase into its subunits and liberation of molybdenum from the protein are simultaneous events during enzyme denaturation (Fig. 6).

Electron paramagnetic resonance properties of the metal centers. As isolated transhydroxylase exhibited minor amounts of paramagnetic centers, including a resting $\operatorname{Mo}(\mathrm{V})$ species with a resonance around $g$ 1.98. A similar signal was described earlier for the molybdenum-containing nitrite oxidoreductase of Nitrobacter hamburgensis (Meincke et al., 1992). Depending on the preparation, a small signal at $g$ of approximately 2.03 appeared with power and temperature characteristics typical of a [3Fe-4S] 
center (Cammack and Weiner, 1990). Under reducing conditions in the presence of a 50 -fold excess of dithionite, at least three different EPR-active sites could be identified in the range 5$70 \mathrm{~K}$. Comparison with EPR signals reported for a series of molybdenum-containing Fe-S proteins (Lowe et al., 1972; Bray et al., 1983; Cammack and Weiner, 1990; Peng et al., 1994) allowed us to assign the resonances observed with transhydroxylase to two Fe-S centers, I and II, and one Mo(V) center. Below $20 \mathrm{~K}$, the dominant species was the Fe-S center I with $g$ values at 2.087, 1.942 and 1.875 ( $\left.g_{\text {av }} 1.968\right)$. Above $30 \mathrm{~K}$, a second paramagnet, Fe-S center II, was the major species with $g$ values at $2.051,1.955$ and $1.872\left(g_{a v} 1.959\right)$. From the present data, the nature and stoichiometry of the Fe-S clusters cannot be given. Presumably, Fe-S center I $\left(g_{\mathrm{av}} 1.968\right)$ represents a [4Fe-4S] cluster, and center II ( $\left.g_{\text {avv }} 1.959\right)$ a [2Fe-2S] site. Alternatively, both centers I and II could be [2Fe-2S] clusters with relaxation properties similar to those described for xanthine oxidase or carbon monoxide dehydrogenase (Bray et al., 1983; Schübel et al., 1995). Further EPR studies of transhydroxylase at defined redox states will be needed, including spin quantification over a wide range of temperatures and microwave power. Above $70 \mathrm{~K}$, a multiline signal persisted with EPR characteristics typical of a $\mathrm{Mo}(\mathrm{V})$ center with hyperfine couplings from molybdenum and hydrogen nuclei. Although the signals of transhydroxylase appeared within seconds of reduction of the enzyme by dithionite, their catalytic competence has still to be demonstrated.

Reaction mechanism. Molybdenum-containing enzymes other than nitrogenase catalyze oxygen-transfer reactions between water and organic or inorganic substrates (Young and Wedd, 1994). Several of these enzymes exhibit a rather low substrate specifity. Transhydroxylase is the only molybdoenzyme known which reacts with two different organic substrates. The enzyme was named transhydroxylase because it transfers a hydroxyl group between several aromatic compounds (Brune and Schink, 1990b). Experiments with $\mathrm{H}_{2}{ }^{18} \mathrm{O}$ (unpublished results) confirmed that water does not participate in this reaction. Involvement of a diphenylether intermediate has been proposed to explain the intermolecular hydroxyl transfer (Brune and Schink, 1990b). On the basis of the cofactor constitution presented here one could also propose a mechanism consisting of two half reactions: a reductive dehydroxylation step and an oxidative hydroxylation step, with the molybdenum mediating the oxygen transfer.

We thank Leonardo Cobianchi for determination of the N-terminal sequences.

\section{REFERENCES}

Aasa, R. \& Vänngård, T. (1975) EPR signal intensity and powder shape: a reexamination, J. Magn. Reson. 19, 308-315.

Adams, M. W. W. \& Mortenson, L. E. (1985) Mo reductases: nitrate reductase and formate dehydrogenase, in: Molybdenum enzymes, (Spiro, T. G., ed.) pp. 519-593, Wiley \& Sons, New York.

Börner, G., Karrasch, M. \& Thauer, R. K. (1991) Molybdopterin adenine dinucleotide and molybdopterin hypoxanthine dinucleotide in formylmethanofuran dehydrogenase from Methanobacterium thermoautotrophicum (Marburg), FEBS Lett. 290, 31-34.

Bradford, M. M. (1976) A rapid and sensitive method for the quantification of microgram quantities of protein utilizing the principle of protein-dye binding, Anal. Biochem. 72, 248-254.

Bray, R. C., George, G. N., Lange, R. \& Meyer, O. (1983) Studies by e.p.r. spectroscopy of carbon monoxide oxidase from Pseudomonas carboxydovorans and Pseudomonas carboxydohydrogena, Biochem. J. $211,687-694$.
Brune, A. \& Schink, B. (1990a) A complete citric acid cycle in assimilatory metabolism of Pelobacter acidigallici, a strictly anaerobic, fermenting bacterium, Arch. Microbiol. 154, 394-399.

Brune, A. \& Schink, B. (1990b) Pyrogallol-to-phloroglucinol conversion and other hydroxyl-transfer reactions catalyzed by cell extracts of Pelobacter acidigallici, J. Bacteriol. 172, 1070-1076.

Cammack, R. \& Weiner, J. (1990) Electron paramagnetic resonance characterization of dimethylsulfoxide reductase of Escherichia coli, Biochemistry 29, 8410-8416.

Carr, S. A., Hemling, M. E., Bean, M. F. \& Roberts, G. D. (1991) Integration of mass spectrometry in analytical biochemistry, Anal. Chem. $63,2802-2824$

Chan, M. K., Mukund, S., Kletzin, A., Adams, M. W. W. \& Rees, D. C. (1995) Structure of a hyperthermophilic tungstopterin enzyme, aldehyde ferredoxin oxidoreductase, Science 267, 1463-1469.

De Beyer, A. \& Lingens, F. (1993) Microbial-metabolism of quinoline and related-compounds. XVI. Quinaldine oxidoreductase from Arthrobacter spec. Rü 61A-A molybdenum-containing enzyme catalyzing the hydroxylation at $\mathrm{C}-4$ of the heterocycle, Biol. Chem. Hoppe-Seyler 374, 101-109.

Frunzke, K. \& Meyer, O. (1991) Molybdopterin cytosine dinucleotide (MCD) is the common molybdenum cofactor in CO-dehydrogenases of carboxydotrophic Pseudomonads, Bioforum 14, 83.

Frunzke, K., Heiss, B., Meyer, O. \& Zumft, W. G. (1993) Molybdopterin guanine dinucleotide is the organic moiety of the molybdenum cofactor in respiratory nitrate reductase from Pseudomonas stutzeri, FEMS Microbiol. Lett. 113, 241-246.

Haddock, J. D. \& Ferry, J. G. (1993) Initial steps in the anaerobic degradation of 3,4,5-trihydroxybenzoate by Eubacterium oxidoreducens. characterization of mutants and role of 1,2,3,5-tetrahydroxybenzene, J. Bacteriol. 175, 669-673.

Hageman, R. V. \& Rajagopalan, K. V. (1986) Assay and detection of the molybdenum cofactor, Methods Enzymol. 122, 399-412.

Holm, R. H. (1990) The biologically relevant oxygen atom transfer chemistry of molybdenum from synthetic analogue systems to enzymes, Coord. Chem. Rev. 100, 183-221.

Hunt, A. L., Hughes, D. E. \& Lowenstein, J. M. (1958) The hydroxylation of nicotinic acid by Pseudomonas fluorescens, Biochem. J. 69 , 170-173.

Johnson, J. L., Hainline, B. E. \& Rajagopalan, K. V. (1980) Characterization of the molybdenum cofactor of sulfite oxidase, xanthine oxidase, and nitrate reductase, J. Biol. Chem. 255, 1783-1786.

Johnson, J. L. \& Rajagopalan, K. V. (1982) Structural and metabolic relationship between the molybdenum cofactor and urothione, Proc. Natl Acad. Sci. USA 79, 6856-6860.

Johnson, J. L. (1988) Molybdenum, Methods Enzymol. 158, 371-382.

Johnson, J. L., Bastian, N. R. \& Rajagopalan, K. V. (1990) Molybdopterin guanine dinucleotide - A modified form of molybdopterin identified in the molybdenum cofactor of dimethyl sulfoxide reductase from Rhodobacter sphaeroides forma specialis denitrificans, Proc. Natl Acad. Sci. USA 87, 3190-3194.

Johnson, J. L., Bastian, N. R., Schauer, N. L., Ferry, J. G. \& Rajagopalan, K. V. (1991) Identification of molybdopterin guanine dinucleotide in formate dehydrogenase from Methanobacterium formicicum, FEMS Microbiol. Lett. 77, 213-216.

Jungblut, P., Eckershorn, C., Lottspeich, F. \& Klose, J. (1990) Blotting efficiency investigated by using two-dimensional electrophoresis, hydrophobic membranes and proteins from different sources, Electrophoresis $11,581-588$.

Karrasch, M., Börner, G., Enssle, M. \& Thauer, R. K. (1990a) The molybdoenzyme formylmethanofuran dehydrogenase from Methanosarcina barkeri contains a pterin cofactor, Eur. J. Biochem. 194, 367372.

Karrasch, M., Börner, G. \& Thauer, R. K. (1990b) The molybdenum cofactor of formylmethanofuran dehydrogenase from Methanosarcina barkeri is a molybdopterin guanine dinucleotide, FEBS Lett. $274,48-52$.

Krafft, T., Bokranz, M., Klimmek, O., Schröder, I., Fahrenholz, F., Kojro, E. \& Kröger, A. (1992) Cloning and nucleotide sequence of the psr A gene of Wolinella succinogenes polysulphide reductase, Eur. J. Biochem. 206, 503-510.

Kretzer, A., Frunzke, K. \& Andreesen, J. R. (1993) Catabolism of isonicotinate by Mycobacterium sp INA1: extended description of the 
pathway and purification of the molybdoenzyme isonicotinate dehydrogenase, J. Gen. Microbiol. 139, 2763-2772.

Krüger, B. \& Meyer, O. (1987) Structural elements of bactopterin from Pseudomonas carboxydoflava carbon monoxide dehydrogenase, Biochim. Biophys. Acta 912, 357-364.

Laemmli, U. K. (1970) Cleavage of structural proteins during the assembly of the head of bacteriophage T4, Nature 227,680-685.

Lowe, D. J., Lynden-Bell, R. M. \& Bray, R. C. (1972) Spin-Spin-interaction between molybdenum and one of the iron-sulphur systems of xanthine oxidase and its relevance to the enzymic mechanism, Biochem. J. 130, 239-249.

Meincke, M., Bock, E., Kastrau, D. \& Kroneck, P. M. H. (1992) Nitrite oxidoreductase from Nitrobacter hamburgensis: redox centers and their catalytic role, Arch. Microbiol. 158, 127-131.

Peng, G., Nichols, J., McCullogh, J. E. A. \& Spence, J. T. (1994) Models for the molybdenum $(\mathrm{VI} / \mathrm{V})$ centers of molybdenum hydroxylases and related enzymes. Geometry, electronic structure, and EPR g-tensor predictions from $a b$ initio and semiempirical molecular orbital calculations, Inorg. Chem. 33, 2857-2864.

Peschke, B. \& Lingens, F. (1991) Microbial-metabolism of quinoline \& related-compounds. XII. Isolation and characterization of the quinoline oxidoreductase from Rhodococcus spec. B1 compared with the quinoline oxidoreductase from Pseudomonas putida 86, Biol. Chem. Hoppe-Seyler 372, 1081-1088.

Pilato, R. S. \& Stiefel, E. I. (1993) Catalysis by molybdenum-cofactor enzymes, in Bioinorganic catalysis (Reedijk, J., ed.) pp. 131-188, Marcel Dekker, Inc., New York, Basel, Hong Kong.

Rajagopalan, K. V. \& Johnson, J. L. (1992) The pterin molybdenum cofactors, I. Biol. Chem. 267, 10199-10202.

Reichenbecher, W., Brune, A. \& Schink, B. (1994) Transhydroxylase of Pelobacter acidigallici - a molybdoenzyme catalyzing the conversion of pyrogallol to phloroglucinol, Biochim. Biophys. Acta 1204, 217-224.

Rüdiger, A., Rüdiger, M., Weber, K. \& Schomburg, D. (1995) Characterization of post-translational modifications of brain tubulin by matrixassisted laser desorption/ionization mass spectrometry: direct onestep analysis of a limited subtilisin digest, Anal. Biochem. 224, 532537.

Satoh, T. \& Kurihara, F. N. (1987) Purification and properties of dimethylsulfoxide reductase containing a molybdenum cofactor from a photodenitrifier, Rhodopseudomonas sphaeroides f.s. denitrificans, $J$. Biochem. (Tokyo) 102, 191-197.
Schauer, N. L. \& Ferry, J. G. (1986) Composition of the coenzyme $\mathrm{F}_{420^{-}}$ dependent formate dehydrogenase from Methanobacterium formicicum, J. Bacteriol. 165, 405-411.

Schink, B. \& Pfennig, N. (1982) Fermentation of trihydroxybenzenes by Pelobacter acidigallici gen. nov. sp. Nov., a new strictly anaerobic, non-sporeforming bacterium, Arch. Microbiol. 133, 195-201.

Schmitz, R. A., Richter, M., Linder, D. \& Thauer, R. K. (1992) A tungsten-containing active formylmethanofuran dehydrogenase on the thermophilic archaeon Methanobacterium wolfei, Eur. J. Biochem. $207,559-565$

Schübel, U., Kraut, M., Mörsdorf, G. \& Meyer, O. (1995) Molecular characterization of the gene cluster coxMSL encoding the molybdenum-containing carbon dioxide dehydrogenase of Oligotropha carboxidovorans, J. Bacteriol. 177, 2197-2203.

Thoenes, U., Flores, O. L., Neves, A., Devreese, B., Vanbeeumen, J. J., Huber, R., Romão, M. J., LeGall, J., Moura, J. J. G. \& Rodriguespousada, C. (1994) Molecular cloning and sequence analysis of the gene of the molybdenum-containing aldehyde oxidoreductase of Desulfovibrio gigas, Eur. J. Biochem. 220, 901-910.

Vänngård, T. (1972) Copper proteins in Biological applications of electron spin resonance (Schwartz, H. M., Bolton, J. R. \& Borg, D. C., eds) pp. 411-447, Wiley Interscience, New York.

Ventom, A. M., Bray, R. C. \& Deistung, J. (1988) The isolation of demolybdo xanthine-oxidase from bovine-milk, Biochem. J. 255, 949956.

White, H., Feicht, R., Huber, C., Lottspeich, F. \& Simon, H. (1991) Purification and some properties of the tungsten-containing carboxylic acid reductase from Clostridium formicoaceticum, Biol. Chem. Hoppe-Seyler 372, 999-1005.

White, H., Huber, C., Feicht, R. \& Simon, H. (1993) On a reversible molybdenum-containing aldehyde oxidoreductase from Clostridium formicoaceticum, Arch. Microbiol. 159, 244-249.

Wootton, J. C., Nicolson, R. E., Cock, J. M., Walters, D. E., Burke, J. F., Doyle, W. A. \& Bray, R. C. (1991) Enzymes depending on the pterin molybdenum cofactor; sequence families, spectroscopic properties of molybdenum possible cofactor-binding domains, Biochim. Biophys. Acta 1057, 157-185.

Young, C. G. \& Wedd, A. G. (1994) Molybdenum: molybdopterin-containing enzymes, in Encyclopedia of inorganic chemistry (King, R. B., ed.) pp. 2330-2346, John Wiley \& Sons, Chichester. 